low-energy beta emitters of long half-life can be made available at low cost and in large quantities. When, however, only microwatt applications are needed, the present sources suffice.

Isotopery was exhibited at both the Palais des Nations and the Palais des Expositions. Most isotope exhibits were in the Palais des Nations. The Russians showed quite a number of their industrial applications and equipment made for process control. The United States' effort, although generally more on the reactor side, gave still a complete picture of isotope applications. The French exhibited a few, but original applications. The United Kingdom isotope applications were shown in the Palais des Expositions placed centrally between exhibits of British industry. These applications illustrated very well the progress of the past three or four years.

The Geneva Congress gave a very good crosssection of all isotope work although, owing to the very full agenda, there was far too little time to discuss single problems in detail. The spirit in general was above all expectations. The sponsors must be congratulated on the choice of papers, and the very smooth organization which they achieved in spite of the short time given to them for the arrangement of the Conference. I feel that, in order to get the maximum benefits out of such interesting meetings, it may be better in future to have the isotope conferences separate from those on atomic energy.

\title{
THE PAMETRADA RESEARCH STATION OPEN DAYS FOR ENGINEERS
}

$\mathrm{F}^{\mathrm{I}}$ VE years ago the Pametrada Research Station, Wallsend on Tyne, held a series of open days for a whole week to publicize the first five years of its existence (see Nature, 165, 963 ; 1950). During the first week of last October, the Station was again opened, to show its further progress. This time there were fifty-three separate exhibits in the laboratories, more than half of which had been developed in the period under review, some showing most ingenious applications of science to the solution of engineering problems in this field. The research association came into existence "to carry out research, to improve and develop complete steam and gas turbine installations and to advise member firms on all matters associated with the design and layout of marine turbines and gearing, and to set up standards of fit and finish required in the principal components of turbine machinery". Its name is derived from the initial letters of its full title: The Parsons and Marine Engineering Turbine Research and Development Association. To see the Research Station in action as the visitors did, ten years after its foundation, was to appreciate the courage and faith of its founders in the value of applying science in their industry. The aim of the director, Dr. T. W. F. Brown, then was, and still is, not merely to keep marine engineering in Great Britain abreast of competition, but also to keep it ahead of the rest of the world.

The value of the site, buildings and equipment now exceeds a million pounds, while there is a staff of more than three hundred. Some of the equipment for full-scale trials of marine turbines is the largest of its kind in the world. No such test equipment existed in the early days of the steam turbine, and this may have been one of the causes of its very slow development in the years immediately following the death of Sir Charles Parsons in 1931. To apply scientific methods to the improvement of marine propulsion machinery to-day, it is of immense value to have test equipment large enough to make fullscale trials ashore.

Most of the work at the Station has been done on the steam turbine; but during the past five years considerable effort has been devoted to improving the gas turbine for marine work, and the experimental 3,500 -s.h.p. marine gas turbine that was on view five years ago has since been run over a wide range of operating conditions and with different fuels. These have shown that, when residual oil is used (which is necessary in marine work for economic reasons) serious troubles are encountered with fouling and corrosion, unless expensive additives are used.

The most impressive exhibit was the experimental gas-turbine rig, in which the combustion chamber and stator were operating at a gas temperature of $2,200^{\circ} \mathrm{F}$. and a mass flow of $5 \frac{1}{2} \mathrm{lb}$. per second. The stator was lined with blades of ceramic material, and the demonstration was shown without the turbine rotor so that the distortion of the stator and combustion chamber could be studied with the combustion chamber alight. This rig will later be fitted with a turbine rotor having liquid-cooled blading, each hollow blade containing a mixture of liquid sodium and potassium metal, to transfer heat down the blade axis to the root embedded in the rotor shaft, which is water-cooled. A special technique is required to handle the liquid alloy of sodium-potassium, which is used as the heat transfer medium, because it is so chemically active in the presence of air and moisture. Means for doing this were shown in another exhibit, the so-called 'dry box'-a glass-sided chamber, in which helium is continuously circulated over the specimens. The design is based on that of a similar chamber used at the Atomic Energy Research Establishment, Harwell, for handling radioactive materials. Impurities in the helium atmosphere of the dry box of 1 part in 100,000 can be detected.

Apparatus was on view designed for studying liquid cooling for gas-turbine rotor blades. A single hollow blade with a suitable liquid enclosed in the cavity was carried at the end of a rotating arm, driven by a steam turbine at speeds up to 11,000 r.p.m., heat being supplied electrically to the extremity of the blade and taken away by water flowing over its root. Exhibits on a smaller scale showed studies of refractory materials such as silicon carbide that are suitable for use as nozzles in uncooled furnace linings in high-temperature gas turbines. One of the several tests to which these parts were subjected was repeated thermal shock, the temperature being changed in a matter of seconds from $1,000^{\circ} \mathrm{F}$. to $2,200^{\circ} \mathrm{F}$., and vice versa, for hundreds of hours.

Research on the steam turbine is at present mainly concerned with the development of a double-casing high-pressure turbine in which the inner barrel exhausts into the annular outer casing, which is therefore subject to exhaust steam pressure and 
temperature and so is relatively cool $\left(400^{\circ} \mathrm{F}\right.$.), when compared with the inlet temperature $\left(900-1,200^{\circ} \mathrm{F}.\right)$. A 4,000-h.p. high-pressure turbine of this type was shown under test. This design is a logical development from a number of successful double-casing lowpressure turbines already in service at sea. Tests have been carried out on a quarter-scale model of this turbine casing to determine the transient distortions of the casing such as may occur during manouvring and under steady-running conditions. Another exhibit in this section was an instrument that has been developed to enable turbine rotors to be rebalanced in their own bearings on board ship at low speeds. The bearing pedestal vibrations were detected by a relative electromagnetic pick-up activated by a tunable mass-spring system that could be tuned to resonance at the turbine rotor speed, so that vibrations at this frequency were highly mag. nified. By suitable attachments the vibrational velocity, which is proportional to the out-of-balance resultant force, and the position of this force around the shaft from a reference point were indicated, to provide the information required for rebalancing.

The staff at Pametrada have become famous for their application of electronic techniques to the study of noise and vibration on ships at sea, very largely due to the inspiration and leadership of the late Mr. H. G. Yates, senior designer. Specialist instruments have been designed for this work, including a portable vibration-meter, MuirheadPametrada wave analyser, low-frequency wave analyser, automatic wave analyser and electronic torsiograph. The use that has been made of such equipment on board ship has now made it possible for the vibration characteristics of even the most complicated gear and turbine machinery to be predicted in the design stage with a considerable degree of accuracy.

Much attention has been paid to the improvement of transmission machinery, both by the study of toothed gearing of all kinds and by the design and testing of hydraulic reversing transmissions, of which a working model was on view. Six scale models in 'Perspex' showed the space requirements, machinery weights and fuel consumptions for comparable machinery installations of various types designed for a power of 10,000 s.h.p. Present-day requirements of steam turbine, gas turbine and diesel engine were shown by the first three, which could be compared with the others - a high-temperature high-pressure steam turbine set, a high-temperature gas turbine with water-cooled blading, and a steam turbine set supplied with steam from a nuclear reactor.

It was shown that during the past decade the cost and weight of marine turbine and transmission machinery has been reduced by 15 per cent and 50 per cent respectively, while efficiency has been improved 12 per cent. An impressive array of pictures of ships engined by Pametrada designs was on view, the total shaft horse-power of those completed and already in service exceeding 21 million. A recent change of policy has led to installations of Pametrada design being built by two licensees in Holland and one in Canada. The hope of those responsible for the exhibition is that owners of ships having seen it may go away and order the most up-to-date machinery embodying the results of this research, instead of being content with conventional designs.

\section{CHEMICAL RESEARCH LABORATORY, TEDDINGTON OPEN DAYS}

$\mathrm{T}$ HIS year the Chemical Research Laboratory, Teddington, of the Department of Scientific and Industrial Research, held its open days during September 27-30, and again the invitations attracted a large number of visitors from government depart ments, industry, universities and schools. Some of the outstanding exhibits by the six research groups are briefly described in this article.

A feature in the Corrosion of Metals Group was the illustration of advisory services to industry, public bodies and other inquirers. These services, which constitute an important part of the work of the Group, were depicted in two ways : one gave typical inquiries and replies in summary form, the other showed selected letters and the replies almost in full. The questions and answers dealt with a wide variety of subjects and from diverse sources, such as an interested layman, a county surveyor and a research association. The information supplied is based on general corrosion science and on the knowledge gained either in ad hoc investigation or in fundamental researches within the programme of research of the Group.

The results of radioactive tracer studies of corrosion inhibition were illustrated graphically. Potassium chromate containing a proportion of radioactive chromium atoms is used, and the amount of chromium found on a steel surface after immersion in the radioactive solution is estimated from the amount of radiation emitted from the surface. Using this technique, it has been shown that during immersion in chromate the growth of the protective film containing chromic oxide on the surface of the metal obeys the same law as the formation of a surface film of ferric oxide during exposure of steel to air. One exhibit illustrated the work being carried out on the development of tarnish-preventive wrappings for use with copper, silver and their alloys. The access to the metal of hydrogen sulphide (small traces of which in the atmosphere are responsible for tarn. ishing) is prevented by incorporating in the wrap a substance that absorbs the sulphide or converts it to an innocuous compound, or acts as a barrier. A number of additives have been found effective. They include chlorophyll, certain salts of chromic, nitrous and phosphoric acids, hydroxides of certain metals, and tannins with and without the addition of alkali. The investigation is still at an experimental stage, but the results of laboratory tests have been confirmed by exposure in an outdoor shed, and in a sideboard and over a mantelpiece of a living room. Patent applications have been filed both in Great Britain and abroad, the exploitation of these patents being in the hands of the National Research Development Corporation.

The exhibits on view in the Inorganic Group covered the three main lines being pursued by the Group, namely, the preparation of pure elements, the separation of the rare earths and the search for useful elements in wastes and low-grade materials. The 